\title{
Abandoning Truth is Not a Solution. A Discussion With Richard Rorty
}

\author{
- Marcin Kilanowski -
}

\begin{abstract}
Richard Rorty suggests that we should stop looking for something common to us all, for universal justifications and truth. Rorty argues that focusing on a single truth sooner or later serves those who claim that there is a proper, true model of living. In the end, they use violence and cause pain, as they are driven by the idea that everyone should accept their truth. In this article I shall argue that such reasoning is not justified and whether we are universalists or constructivists, our actions may be the same and cause pain. At the same time, having the same beliefs will not stop us from acting differently. What matters is how we use a particular concept in accordance with our interests and not the concept itself. I shall also argue that dialog can help to prevent violence and that while Rorty is right, there are also a number of problems with that proposition.
\end{abstract}

Keywords: Richard Rorty, constructivism, universal justification, truth, interests, dialog.

Published online: 30 September 2018

\section{Introduction - Grand Ideologies}

As the category of truth was (and still is) deeply embedded in social processes, one of them being the dissemination of beliefs, Richard Rorty, one of the most important philosophers of the 20th century and often considered a postmodernist, suggests that we should abandon this concept altogether. Prima facie, it is difficult to disagree with him when we consider the history of the $20^{\text {th }}$ century - a century of grand ideologies.

The grand ideologies of the $20^{\text {th }}$ century aimed to make the world perfect and all individuals happy, or at least those worthy enough to achieve the state of felicity. Those ideologies provided descriptions of historical processes and, on that basis, pointed in which direction history, out of necessity, would unfold. Their particular persuasiveness was based on the way they depicted difficult-to-describe socio-political and economic processes as a whole. Their strength rested upon constantly addressing individuals, fellow citizens, and upon shaping their way of thinking. Their "success" (as ideologies) was based not only on defining a clear goal, but also on this goal being accepted by all

\footnotetext{
Marcin Kilanowski

The Nicolaus Copernicus University in Torun

Faculty of Law and Administration

Department of Theory of Law and State

ul. Władysława Bojarskiego 3

87-100 Toruń

e-mail: markil@umk.pl
} 
the members of the society as their own. Building a new, better world was made possible due to the involvement of each individual.

We can say that the leaders and strategists of these ideological trends realized, in a perfect way, the categorical imperative of Kant. They aimed at convincing individuals that they are not merely the means of achieving a given goal, but that they are the goals themselves. Of course, today our judgment concerning what happened in the past will differ from that of communists and fascists. Today, we would undoubtedly deem all despotic, authoritarian systems, in which an infallible, omniscient leader wished to make us realize our desires and to take care of our interests, were de facto the total enslavement of individuals. Human beings were humiliated in the name of realizing a given goal, former rights were negated, and human dignity became something owned only by those belonging to the privileged group. People were treated as objects, merely as the means of realizing a given goal. But such an evaluation is ours alone, and a retrospective one at that. Perhaps it was shared by others when their individual, weak voices were suppressed by roaring megaphones and the accompanying applause of the mob. At a particular moment, the overwhelming majority believed - indeed, were convinced - that this is "human being", both the means and the goal, and that the maxim guiding their actions should become a universal law. ${ }^{1}$

\section{Rorty against Truth}

In light of the above, we could say that at a particular moment of history we can be provided with different possible accounts of a situation, and the success of one of them is a result of its dissemination. If that is the case, it seems that it is of little importance whether we believe that there is some truth that we have discovered, or we are convinced that our propositions are only a manifestation of historically changeable beliefs - whether we will refer to the category of "truth" spelled with a capital " $\mathrm{T}$ " or lower case letter, whether it will be an absolute Truth or an accidental, temporary, local truth. The important issue is not whether things are "actually" this way and not another. It will not be of much significance whether, in order to achieve a given goal, the adherents of an ideology refer to a lie, repeated a thousand times so that it becomes "truth," or to an objective truth, if it can be discovered at all. What marks a particular belief, and the actions accompanying it, as "right" would be their being useful for achieving a given goal and the general acceptance of the course set. History teaches us, according to such a view,

\footnotetext{
${ }^{1}$ Referring to Kant in such a context may seem out of place. Usually, while considering the sociopolitical transformations of the $20^{\text {th }}$ century, there is a tendency to refer to Hegel, Marx and Sorel. But there is a presupposed universal "ought" in all the ideologies that proceed from these philosophies. In this regard, one might as well speak of Kant as of any later philosopher. Due to this, reference to the philosophy of Kant as the source of the rise of authoritarianism is often present in the work of Isaiah Berlin. See, for example, Berlin (1991): 232.

${ }^{2}$ The reference here is to the words often attributed to Joseph Goebbels: "Repeat a lie a thousand times and it becomes the truth," or "if you tell a lie big enough and keep repeating it, people will eventually come to believe it." Goebbels did refer to the "Big Lie" idea, but no reliable evidence has been found for these attributions, first associated with Goebbels by the US House Committee on UN-American Activities in 1946, see United States (1946): 19.
} 
that anything may become a truth when the appropriate effort and energy are devoted to its promotion and when using the weakness of those we wish to convince. We can succeed when the party to be convinced ceases to ask questions and offer counter-arguments. What counts is the overwhelming and captivating power of some content - both literally and metaphorically.

Being aware of the present methods of manipulation, we can say that it does not matter what things "actually" are; what does matter is that certain contents are considered, in the age of grand ideologies, to reflect the only right truth. Even so, we should be aware, as Richard Rorty claims, that they are really historically and culturally determined. In short, searching for one universal truth about the world and human beings does not matter, Rorty insists: we will not accomplish anything worth achieving in this way. This is why he suggests that we should relinquish any reliance on the "Platonic" idea of something common to us all, something uniting us with others, and that we should cease the search for both universal justifications and truths. ${ }^{3}$ Rorty therefore writes that those such as Nietzsche or Heidegger should privatize their projects, their pursuit of the sublime, consider them as irrelevant to politics, and as such reconciled with the sense of human solidarity, supported by the development of the democratic institutions. This "amounts to the request that they resolve an impending dilemma by subordinating sublimity to the desire to avoid cruelty and pain." 4

Rorty goes one step further and claims that if we relinquish our reliance on the category of truth, we would eliminate the problem connected with the emergence of fanaticism, fundamentalism, or totalitarianism, for which, according to Rorty, the presence of truth is both the starting point for imposing opinions upon others and contributes to our utilization of violence. Rorty's fear, which he backs up with examples from history, is that talk of something that unites us may serve those who will claim that there is one true model of living, of collective cooperation, and that only one form of social and political organization is right for us all. If there is a truth about human beings, about relations with others, then in accordance with the traditional way of thinking, we should act on it, and any opposing action, such as freethinking, should not occur. Each and every human being, they may insist, should act according to fixed overt standards, and those who disobey should be directed onto the right path.

As Rorty suggests, the idea of one absolute or universal truth should be replaced with a series of minor truths, local justifications, relativized in certain circumstances. According to his perspective, we can call true any stance that has been commonly created and accepted, and the search for objectivity is nothing but the pursuit of an inter-

\footnotetext{
${ }^{3}$ It is worth adding that Rorty takes "Platonism and Greek thought generally to say, the set of candidates for truth is already here, and all the reasons which might be given for and against their truth are also already here; all that remains is to argue the matter out. [...] If one holds the Greek view, then it is reasonable to define truth in terms of idealized rational acceptability in the manner of Habermas, Peirce, and Putnam. But that definition will be useless once one starts thinking of languages and truth-candidates as constantly in the process of change." Rorty (1996): 50-51. He also writes: "It is not that there is anything wrong with reason, truth, and knowledge. All that is wrong is the Platonic attempt to put them in the center of culture, in the center of our sense of what is to be a human being"; Rorty (1996): 27-28. On that issue see also Rorty (2015): 875.

${ }^{4}$ Rorty (1989): 197. For a contrasting view, see Engel (2007).
} 
subjective understanding. And, as Rorty claims, such a belief "goes hand in hand with the thesis that no language is more adequate to reality than any other language." 5 Thus one can, for instance, become a doctor and help others not because of the supposed universal humanity uniting us, but because one's father was a doctor as well, and people were grateful to him and respected him. One could also be a Russian soldier in occupied Poland and, despite the curfew, help to bring a doctor to a woman about to give birth, because somewhere in Siberia, he had left his own wife who was also about to give birth. ${ }^{6}$ The justifications of these actions may be private, local, and still so significant that they will even affect the attitudes of others. Rorty therefore argues that we are left with our acknowledgement that we are rooted in a particular tradition, community, culture, historical time, or particular way of thinking. And the awareness of locality shapes our belief that our truth does not need to embrace everything, that it is, just as we are, a result of the time, place and social beliefs that are held. ${ }^{7}$ In such circumstances we should rely on "sentimentality" and "sentimental education" instead of on one single truth. Such an education should not be based on ingraining moral truths or assigning moral obligations, which have nothing to do with love, friendship, trust, or social solidarity, but with developing our sensitivity to the situations of other people. ${ }^{8}$

Rorty claims that when we no longer rely on the category of truth, we have no choice but to acknowledge the contingency of choice, history, and situation. We will be closer to realizing that our judgments, whatever they are, are not the only ones. Thus, according to Rorty, we will not try to force others to change their point of view and adopt our own, for ours will be just one of many possible points of view. We will understand that our societies "are not quasi-persons, they are (at their liberal, social democratic best) compromises between persons." 9 A period of dialog and the sharing of opinions will take place. Violence will end, for what divided us - a belief that we are in the possession of the best and only true vision of the world that must be accepted by others - will be rejected as a fantasy, as an expression of longing for the feeling of safety and security that used to be present in the period of our childhood, as Isaiah Berlin says. ${ }^{10}$

\section{Is Rorty right?}

At this point, it is worth asking whether an awareness of locality actually eliminates tensions. Would doing away with the category of "Truth", in the name of which many fought and died, guarantee peace? Should we fear universal truths and justifications? We will consider these issues by using an example: What difference does it make that we acknowledge private property (property law, inheritance law, commercial law - all of them are based on the category of property) as the foundation of our civilization as a result of the

\footnotetext{
${ }^{5}$ Rorty (1997): 22.

${ }^{6}$ This example is a personal one. The Polish woman about to give birth was actually my grandmother.

7 Rorty (1991B): 30, 214. See also Rorty (2008): 17.

8 Rorty (1993): 122.

${ }^{9}$ Rorty (1991A): 196. According to Rorty, freedom is also a compromise. This freedom seems necessary to achieve the aim of liberal societies. This aim is not "to invent or create anything, but simply to make it as easy as possible for people to achieve their wildly different private ends without hurting each other." Ibidem.

10 Berlin (1991): 33.
} 
historical, contingent, or cultural evolution of communities and state institutions? We can just as easily claim that a social structure based on property is the only right and "True" social structure. In both cases, property defenders will fight with equal fierceness when someone else decides to seize their property or to initiate changes due to which private property will cease to exist tomorrow. Conflict will arise regardless of whether we consider private property to be the basis for all social relations as being a local truth or a Universal Truth. The parties in question will fight equally fiercely for both the former and the latter. In short, conflict will ensue regardless of the awareness of the accidental character of what is being fought for. Accordingly, considerations about whether we are faced with one, and only one, all-embracing Truth, or with minor, local truths is of little practical importance; it is also not justified in either case to resign from or avoid just one of these alternatives.

It seems, then, that Goodwin, Proudhon, and/ or Chief Seattle, and not Rorty, were closer to identifying the main problem of Western civilization, a problem that constantly generates conflicts. Violence will appear where there are those who own things and those who wish to deprive them of their possessions. ${ }^{11}$ We can look for justifications, referring to truth, God, or historical necessity, or to the fact that the majority suffers from hunger. In order to end the strife, it is enough just to reach in the right direction. Such references are aimed at strengthening one's position and proving that the path taken is the right one. But it does not matter whether we refer to truth or God or the destiny of history if we make practical consequences our main consideration. Instead of shouting, "It is the absolute truth that we are privileged, and we have the right to all the existing resources," one may cry, "We are hungry, and we want to satisfy our hunger with what you own." The effect will be the same whenever there are too many of those desperate, shouting people. In such situations time will come for resorting to violence.

It is worth recalling that all the revolutions and wars of recent centuries were fought to a great extent as a result of the dissemination of propaganda; the theories of class struggle, for instance, or of a chosen people that were applied to historical circumstances constituted major support for the claim that war was justified. Nonetheless, they were fought in terms of practical goals and this continues to be the case. We can say, therefore, that theories and ideas are crucial for realizing practical projects, but it is important to be aware, in contrast to Rorty's way of thinking, of the fact that it is of no importance whether the makers and justifiers of war refer to one absolute or local truth, or whether they do not refer to any truth at all. In short, seeking moral or historical or religious support in referring to the category of truth does not determine who we are; thus, there is no need to do away with it as the reason for given actions. Regardless of whether we refer to metaphysical truth or to the truth of a particular culture (a local truth), we can use either of them to achieve the same goals. The same kind of truth may also help in justifying the efforts to achieve completely different goals. ${ }^{12}$ This can be illustrated using

11 See Lamb (2009); Proudhon (2008); Kaiser (1987).

${ }^{12}$ The influence of theory on practice is not questioned here. If we create a theory of racial and cultural differences, it will undoubtedly influence the way we perceive the world. However, the way we treat others will not result from a particular theory, but rather how it is used. If, according to our theory, we consider somebody "backward," for example, it is not obvious that we will automatically wish to subjugate or change him or her. We can just as well accept or tolerate or leave that person alone. 
the example of the belief that it is an objective truth that God exists and we are sinful. When approaching human beings as erring and sinful, we may reach the conclusion that mistakes should be forgiven and neighbors should be loved, not hurt, especially when we are not blameless ourselves. But we can also say that since people err and are sinful, they should be punished, and sins should be called out and defeated, even by burning someone at the stake. And this is how it was in the past: violence directed at others was justified by referring to the truth. But these were just categories at the service of men who endowed them with meaning via their particular usage.

Yet another example is the social division we could effect by grouping people into the lethargic and the energetic. Applying this distinction, we could prove that this is their objective nature, or that it is culture that has shaped our way of thinking in such a way that we perceive some as energetic and others as lethargic. However, the fact that we recognize those who are energetic as being more useful for a society, and automatically as more valuable and more important, will actually be a particular use of this belief, whether we see the belief as metaphysical or as shaped within our culture. Such an attitude can appear whenever we believe in one thing rather than another. However, whether it refers to some natural or cultural premises, the same division into the lethargic and the energetic may form the basis for considering the differences between people as something that should be accepted.

\section{Usage and Interest}

The belief that there is some truth or something else which is common to us all does not need to lead to the determination of one true and universal path to be followed. Such a claim about one right form of conduct is nothing but a particular usage of this belief. We can well imagine that what is common to us all is the proof that everyone has what we have, for example, that we are human beings with inherent dignity, and that we should therefore respect each other. We can claim that each and every human being has the right to individual development to the extent they deem appropriate, and no one has the right to "mould" any of them according to a vision contrary to their own, even if they act in unexpected ways, for their right to individual development is more important.

With respect to the above, we can say that beliefs, including the metaphysical views that Rorty fears so much, do not as such determine a particular attitude or a set of such that influence actions just by virtue of holding them. A given attitude results from the use of such a metaphysical belief. The use is, on the other hand, determined by the interest guiding a particular person. ${ }^{13}$ Therefore, when talking about our actions, it can be claimed that it does not matter whether our vision of the world is founded on objective or culturally constructed premises, or whether it describes the actual state of affairs, or whether it results from a commonly accepted social construct which has been recognized as valid in the course of the process of its dissemination. ${ }^{14}$

\footnotetext{
${ }^{13}$ Interest is something different from belief and is affected by emotions, needs, socialization, habits, and so on.

${ }^{14}$ It seems certain that as long as we share some opinions that take part in shaping our vision of the world, this vision becomes our reality: it determines our scope of thinking and acting. Still, we should be aware of the fact that subjective beliefs often become objective when they are believed to
} 
To make this clear, let us focus on another example. Let us imagine that a country believes that in the distant past, a particular territory used to lie within its borders. On this basis, the country then advances a claim that this is how things should still be. Of course, the country that is currently in possession of the territory is not enthusiastic about returning it, and war breaks out. If, however, the first country declared that indeed, historically, the territory did belong to it, but it no longer wants this territory, there would be no claim for regaining the territory and there would be no war with the neighboring state. The claim itself will change together with a change in the interest that is the basis for using a belief. It is not necessary to change a belief in order to change a claim. Present attitudes may stem from the belief that all historical events should not influence the way in which we create common space for communication for different nations. We can claim that after a bloody history lesson we arrived at the conclusion that it is not these ideas of state, nation, ethnic state, race, territory, etc., that are the most important, but it is the people who used to be pushed into particular frames of interpretation - the frames of usage.

In other words, behind any metaphysical beliefs about something internally common to all of us stands the recognition that because we are all the same, only one attitude is appropriate, or perhaps we are all the same, but our individual choices may be different. Here lies the particular interest of those who prefer one explanation over the other. The one who wishes to subjugate everyone else, who wishes to organize the surrounding world according to his or her plan, is also guided by a particular interest. Of course, those who wish to accept the diversity of attitudes adopted by those like us will defend their interests too, to give people the right to individual development.

With such an approach, one can wonder whether the constructivist perspective is actually the more convenient one; one can believe that it is, after all, more susceptible to change. In the case of the metaphysical belief that there are the chosen and the damned, the better and the worse, that there are the privileged and the untouchable, ${ }^{15}$ not much can be done. This is simply the way things are for metaphysical belief. But in the case of social constructs, on the other hand, it can be claimed that this is not necessarily the way things need to be, that it is enough to change our perspective and we will no longer distinguish one from the other, and the problem will disappear. Thus, recognizing the cultural foundations of our way of perceiving the world seems more convenient, for they can be changed when we need to do so. But this account of convenience is just an appearance. For a constructivist who acknowledges the cultural character of our beliefs about objectivity or universalism, it should be clear that those are not so susceptible to change as we would wish them to be, especially when a problem is identified from a particular perspective. It will be difficult to change our way of cultural description once

be such by the majority. Therefore, there is little practical difference between objective reality and a popularized belief that actually is no longer a belief but our "objective reality." Ultimately, only a few make the effort to remember that what initiates our beliefs are temporary assumptions or social conventions. The more comfortable we feel, the more familiar within a certain set of beliefs we feel, and the quicker we forget about their origins.

${ }^{15}$ Reference to the people in India belonging to a group of very low social status-untouchables-deprived of some rights and discriminated by the rest of the society. For more on the issue, see Deliege (2001). 
we become, over years, accustomed to perceiving people in a given way. Of course, we can change our cultural convictions, our descriptions, or our language with time; but the problem of use and the particular interests underlying them will remain. As I said above, cultural conviction as such is not what determines our choices, whether social or political. Even if we do away with one opinion, another will always appear. If the mechanism of usage and interest remains the same, a change in opinions will not matter and whether we call somebody "Gypsies" or "Roma," for example, will not prevent us from excluding them socially, humiliating them, or being violent in reference to them. ${ }^{16}$

For further clarification, it is worth adding here that, together with a change in the beliefs of the parties participating in a discussion, their claims may change as well; but they do not necessarily need to. This will depend on the interest they are guided by, which will surely influence any particular use of a belief. Knowing all this, to maintain that we should alter our beliefs in order to change our claims is to introduce unnecessary and misleading simplification, and, at the same time, to return to where we have been before. An exchange of beliefs as such will not give us much if it is not followed by a change in their use. We will replace them with other ones, behind which particular interests will be hidden, and, quite often, the very same interests. The same can be said about the category of truth. It does not mean much itself unless it is used for forming an attitude. The fact that one can distinguish the Aryan race from other races, for example, means nothing until somebody states that the Aryan race is better than other races, for they deem particular traits as more desirable than others, and so Aryans should be the only race to rule. To sum up, it can be said that by failing to recognize the role of the interest hiding behind a particular use of a belief, we may get the impression that these are the beliefs (for instance, that truth is absolute, or local, or that there is no truth at all) that are responsible for our claims, and therefore we may hold that what a change of a particular belief can result is change of claims.

Finally, it is worth repeating that we should not seek to rescue humankind from rejecting the category of truth or universality, as Rorty does. The project of abandoning deliberations about truth does not give us much, and it does not in the least lead to the emergence of dialog and peace, as Rorty would wish. In the name of "Asian values," for example, there are many who might kill in the same way as those who kill in the name of universal ones. ${ }^{17}$

\section{Dialog}

Although it is impossible to agree with Rorty that simply refraining from using the category of truth can change our conduct, it is acceptable to agree that dialog and discussion provide us with the opportunity to initiate changes regarding the attitudes adopted.

\footnotetext{
${ }^{16}$ It did not change much in the long term to call the untouchables in India by the name Harijan ("People of God") - a change that was initiated by Mahatma Gandhi. For the origins of the term, see Srivastava (1997): 15.

${ }^{17}$ Invoking "Asian values" often occurred to justify a particular code of conduct exercised by authoritarian regimes in Asia, which referred to the belief in the existence within Asia of a unique set of values that reflected their specific regional culture, see Osiatyński (2009).
} 
Here, Rorty's intuition to advocate dialog seems right. Such dialog will undoubtedly be favorable as long as it facilitates getting to know one another and allows arriving at a harmonious way of using particular beliefs. We can imagine a situation in which conflicting claims between parties may be settled due to our dialog. Discussion might end the dispute and no one has to suffer. All this will, of course, depend on which way of using a given belief prevails, and on what interests the parties have agreed. When we encourage someone to use violence against a third party and not against each other, the conflict and violence which Rorty wished so much to avoid will appear between the disputant and the new victim. ${ }^{18}$ Such dialog, the role of which was to prevent violence and suffering, merely shifts them elsewhere. Of course, in such circumstances, we can say that the opportunity for communication was not used in the right way.

But what does "using something in the right way" actually mean? Rorty would say that the way is right as long as it is in accordance with our cultural and social hierarchy of values, which attains its justification from within our local community. For liberals, Rorty would add, it is important for the hierarchy of values to be directed towards the protection of individual, private spheres and the establishment of such a public sphere within which the former will be able to seek agreement and consensus. ${ }^{19}$ However, such an explanation would not be really useful; it remains open as to which values of our local community guide us, whether they are actually what we take them for, and especially, what it means to believe that we should protect individual private spheres and support the establishment of a public sphere focused on the search for consensus. ${ }^{20} \mathrm{We}$ face the very same obstacles when facing members of other communities or cultures. ${ }^{21}$ Without reference to our culture or historical roots, we may add to Rorty's claim that the "right

${ }_{18}$ This is, in some sense, the case with international corporations which abide by international standards concerning human rights in Europe or in the USA, but when they conduct business in Third World countries, they use the lack of internal legal regulations as a license to ignore and violate those same rights. They agree, in an active or passive way, on coercion with respect to the citizens, or even on whole political regimes, which enable the corporations' investments to increase in value. Moreover, using such violence is often possible due to the presence of corporations and the role they play in financial and technological support for the existing regimes. For more on this issue, see Deva (2012). ${ }^{19}$ See Rorty (1989): 197. Rorty believes in a particular set of values that were crucial for the Enlightenment. For example, Rorty ascribes a special significance to suffering. In light of that we can ask: does he not uncover a common denominator for us all, a thing characteristic of a liberal metaphysician, when he points to the susceptibility to experience humiliation and pain that we all share? Such a common denominator is to serve the metaphysician to describe his own self and to describe his relations with others, for both private and public purposes. Answering this question, one could come up with an interpretation according to which Rorty does indeed introduce a certain common denominator for all human beings. This is why some philosophers like Bernard Williams go further and tend to see Rorty as a universalist of some sort. However, what is more convincing is the comprehensive vision of liberal modernity presented by William Curtis, which features a virtue-based conception of the liberal democracy of Richard Rorty, see Curtis (2015).

${ }^{20}$ Does it mean the sort of protection of the private sphere as in the Kiobel v. Royal Dutch Petroleum Co., 133 S. Ct. 1659 (2013), in which the Supreme Court of the USA rejected the claim concerning the violation of human rights by international corporations in Nigeria? Does this mean searching for consensus in the public sphere (based on the values of our democratic community), which would be based on believing that our understanding of these values does not allow determining whether they were violated in another state?

${ }^{21}$ It may be the case that we relate to them to a greater extent than to our own neighbor. 
way to use dialog" is one that does not exclude, does not deem anybody to be worse, as inhuman or subhuman. One may observe a certain historical tendency in human behavior: if one deems someone else or some group to be worse, then one is close to using this belief in order to exclude the worse, treat those persons in an unkind way, or use violence against them.

It is worth adding that for Rorty dialog concerns the public sphere and is undertaken in public language. ${ }^{22} \mathrm{He}$ argues that we should use two separate languages: private and public if we do not want any more violence and exclusion. We should also ask whether we are willing to agree with Rorty and assume that a sharp division into the private and the public is indeed possible. Is the fact that while acting we should think of others and should take into consideration their final vocabularies not an encouragement for us to consider the arrangements from the public sphere while shaping our private vocabulary? Moreover, does it not mean that, at the same time, we are not able to make a clear distinction between what is private and what is public? Indeed, it is hard to imagine ourselves being able to use a final vocabulary including both a private and a public sphere, but acting only in accordance with one of them. ${ }^{23}$ It is difficult to imagine ourselves hating enemies on the one hand, and acting so as not to humiliate them and not to make them suffer on the other. ${ }^{24}$ Finally, it is hard to imagine someone who is a nationalist using a private vocabulary full of expressions of hostility toward foreigners, their beliefs, their culture, and their religion while praising liberal freedoms for everyone in their public vocabulary. In short, it is difficult to envisage a situation in which, on the one hand, we describe ourselves and others in our private vocabularies and these descriptions would have nothing to do with someone's present or prospective suffering - and, on the other hand, we consider causing suffering the worst thing we can do. Unfortunately, the doubts that arise from the discussion of the sharp division into the private sphere and the public sphere are not clarified in Rorty's works. While reading them, we encounter fragments that point to the relations between private and public vocabularies. They indicate how the private part of the final vocabulary affects the public one, and vice versa, and how the public context influences the shaping of private vocabulary. ${ }^{25}$

Rorty's reasoning relies on the potential to distinguish between two independent portions of our final vocabulary, and on separating the private sphere from the public one. Such a distinction seems difficult to maintain, as the public sphere is subject to constant changes due to the activities of individuals, which transcend their private spheres. ${ }^{26}$ It is also difficult to separate the private from the public, because of the fact that the former, to a great extent, constitutes the latter. What can be done, however, is to point to the relations between the two. Even if we assumed that within our vocabulary

\footnotetext{
22 Rorty (1989): 100.

${ }^{23}$ Brandom (2000): 178.

${ }^{24}$ On criticism of Rorty's antifoundationalism being compatible with his prohibition of cruelty, see Guignon, Hiley (2003): 139-150.

${ }^{25}$ Rorty (1989): 41, 96. Also Rorty (1996): 40; Rorty (1992): 593; Rorty (1991A): 80.

${ }^{26}$ This is the point often made in the commentaries on the philosophy of Richard Rorty. See Auxier, Hahn (2010).
} 
it is possible to distinguish the portions of it that are more private and more public, any change that would occur within any of them would be a consequence of their affecting each other. The conclusion to the above is as follows: it is impossible to separate the private sphere from the public if, at the same time, dialog and freedom of speech are to be maintained. The interactions between them are necessary for social harmony and individual growth. In other words, this is not the way to defend both the private and the public sphere against threats. ${ }^{27}$

What is crucial in the course of dialog are also different interests. Unfortunately, Rorty does not mention this, therefore we should add that when advocating dialog, it is worth believing that in the best possible scenarios the disputing parties will debate long enough and will explain to each other all the controversial issues, that they will also discuss the interests guiding their actions and influencing their claims. Perhaps they will agree on the interests they should be guided by.$^{28}$ But what is to be done when a disputant does not feel that he or she uses a particular belief under the influence of the interest which shapes his/her claim and attitude? He or she will still think that the attitudes and actions are the way they are because they result from a particular belief (based on absolute truth, universal approbation, or cultural view). Such a person will still justify actions by holding particular beliefs, at the same time feeling absolved from responsibility for these actions. The problem will be significant. As long as we are not aware of the fact that it is interests and beliefs that guide us, we will not be able to accept the responsibility for our actions and it will be impossible to open responsible dialog. Instead of becoming a method for reflecting upon problems based on asking questions and actually listening to the answers, to different opinions and plans, dialog will still occur occasionally, at best eliminating conflict for some time, but it will not resolve the basic problem, which is our lack of understanding regarding our role in taking action (which depends on our interests and claims) and not taking responsibility for those actions.

We can say that dialog is possible, or preferably, "undisturbed", as Jürgen Habermas would put it, ${ }^{29}$ if we consciously suspend our claims and interests and if we acknowledge the freedom and equality of all the parties. The problem does not rest in our beliefs, impeding friendly discussion, but in the claims which affect their use. The claims exist regardless of our beliefs and whatever category of truth we may apply. But is it possible to relinquish those claims? Now, we can imagine that we temporarily suspend our belief that something is either white or black, but it is far more difficult to imagine that we might manage to suspend our claims for a longer period of time and that we enter into a dialog when we want to gain something from the other party, and when the other party incessantly refuses. The situation may become very difficult. Of course, the party wishing to induce the other to adopt their vision or take a particular action will

\footnotetext{
${ }^{27}$ For more on the critique of the private language-public language distinction, see: Kilanowski (2013): 106-112. More on the subject of language and communication in Rorty's philosophy can be found in: Pable (2015).

${ }^{28}$ It is worth adding that those that believe in such a scenario include Habermas, although he is criticized by Putnam. The latter considers continuation of the discussion until everyone is in agreement as a utopian idea, because in the real world an agreement of this sort never happens, even when the discussion is long enough. For more on this, see Kilanowski (2015): 831.

${ }^{29}$ Habermas (1981).
} 
not always resort to coercion when refused. There are issues, however, with respect to which the other party's negative attitude can result in the use of most drastic means, as it is sometimes the case in international relations, for example. ${ }^{30}$

As we can see, an additional difficulty occurs due to our inability to suspend our claims in such a way that it results in the discussion being centered upon telling each other about the world we live and act in. We cannot relinquish our interests in such a way that they do not generate claims. We can try to suspend them, but this will be possible only until we are required to take a decision of some kind. In some circumstances we can postpone that decision for a long time, but sooner or later a point comes at which we have to choose between the particular uses of a belief, for example, concerning the purity of the nation. Sometimes, decisions must be made very quickly, since what is at stake is exclusion from a privileged group, and it is important whether to accept the division introduced or to oppose it. ${ }^{31}$ Usually there is ample time for reflection and discussion, but this time is not used. When a problem arises, instead of making the decision individually, one transfers it onto others or some beliefs one holds. ${ }^{32}$ Those others, often with great eagerness, are content and accept the role of deciding; they use the lack of awareness in their decision-making, which "proves" that there is no other way to act, for this is the nature of our beliefs. ${ }^{33}$

As we can see, dialog does not exhaust what should be achieved. Dialog is a means of achieving particular goals. Dialog as such cannot be the goal whose achievement discourages people from fighting, from using violence. We can sigh, "if only that were possible." Disputes about ethnic minorities, foreigners and refugees go hand in hand with the presence of these groups in the countries where they appear. Despite this process being an ongoing one, not everyone seems satisfied with the presence of such groups and thus we learn about the ensuing tragedies, aggressive attacks, and violence.

Dialog, that is, free and undisturbed communication, is undoubtedly a value, but we need to specify in the name of what it is to occur. It may concern the ways we describe the world to each other, or perhaps it can be aimed at defending a belief, but it is in our interests to see it exercised. For some, what is crucial is the belief that the human being is of value, and this belief is accompanied with it being used in a particular way: on the

\footnotetext{
${ }^{30}$ In some way Rorty is aware of that and he says that when dialog fails there is nothing left but the use of force. Rorty writes: "Those words are as far as he [its user] can go with language; beyond them there is only helpless passivity or a resort to force." See Rorty (1989): 73. Rorty is not the only one who believes in the liberal values of openness, tolerance and dialog, but sees the use of force as the means of dealing with the conflict. Such a way of reasoning can also be found in the work of Isaiah Berlin, see Berlin (1998): 30.

${ }^{31}$ That was the case with Sophie Scholl, who said before her execution: "How can we expect righteousness to prevail when there is hardly anyone willing to give himself up individually to a righteous cause. Such a fine, sunny day, and I have to go, but what does my death matter, if through us, thousands of people are awakened and stirred to action?" Gebel (1946/1983). See also Hanser (2012). ${ }^{32}$ This process was very well described by Ortega y Gasset and Erich Fromm, among many others. See Ortega y Gasset (1994); Fromm (1994).

${ }^{33}$ Such a path of reasoning is often advocated by those who wish to defend a particular status quo. They are not only the leaders of regimes with subordinate state apparatuses, but quite often are also professional groups who follow the ideology of legalism. See Shklar (1976).
} 
basis of the belief, they are against using violence towards any other human being. ${ }^{34}$ Although both the particular belief and its use are rooted deeply within all of us (and it does not matter whether recognizing human beings are of value is a universal or a local truth), we should be ready to discuss them and want to justify such beliefs and to extend our knowledge about the topic through meeting other people, by getting to know them. We should also be ready for both the belief and its use to change to some extent due to the dialog. It might transpire that in our desire not to hurt or harm we actually unconsciously make someone suffer. ${ }^{35}$ And perhaps regardless of whether someone is right, or whether some are more talented than others, whether some do have greater opportunities for succeeding in realizing particular tasks and others do not, etc., we can still convince our disputant that such matters are not a basis for deeming some worse and others better, rewarding the latter with the right to become the masters of life and death with respect to all the rest. We know this admission does not come easily, and there may be many voices in a discussion, as many as there are attitudes of reluctance to enter into a dialog in the first place. It is important to realize that such obstacles exist in order not to state too optimistically (as Rorty does) that dialog can "liberate" us. ${ }^{36}$

\section{Conclusion}

In the search for a conclusion, it is worth asking the question: are metaphysicians dangerous? Should we fear them as Rorty does? In order to answer these questions, a few words of clarification are required. Along with adopting a certain vision of the world, an attitude of some sort is created with time. This attitude is closely connected with the actions we take. These actions, however, are not a direct consequence of the adoption of a given vision of the world, but are a consequence of its use, the use of the particular beliefs which comprise this vision. Thus, beliefs evoke specific practical consequences, although not due to the fact of our holding these beliefs, but rather this is due to the fact of our using them. Particular visions of the world, a belief, an opinion, may all be affected by different usages, depending on the interests of those who hold them. These beliefs, opinions and visions are not automatically responsible for the conclusions drawn from them concerning the actions that should be taken, attitudes adopted, etc., but it is the one who arrives at given conclusions, the one who adopts given attitudes that is

\footnotetext{
${ }^{34}$ It is widely believed that not everything may be treated as the object of discussion and transformation, as is the case with ius cogens. It is worth remaining open to holding dialog on whether we understand correctly the particular issues relevant to the protection of those ius cogens (who a human being is, what his or her needs are, whether these needs are recognized, whether the actions taken with respect to them are right), for it is these particular issues that determine whether those we wish to protect will actually be protected. In other words, we can say that in our opinion, we should not make soap and mattresses of human beings. See Nałkowska (2000). We will not change such a belief either. It is worthwhile, however, to enter into dialog for we may have seen too little, and in the course of discussion we may realize that we deprive human beings of their dignity when we agree, for instance, on using their corpses for artistic activity (See: Exhibition "The Human Body"); or, perhaps, we can see this same dehumanization when corporations make human beings "guinea pigs" by feeding them genetically modified organisms.

${ }^{35}$ See Kennedy (2004).

${ }^{36}$ For more on the issue of dialog in Rorty's philosophy, see Kilanowski (2017): 64-66. Also Gross (2008).
} 
responsible. Now, the two questions asked above can be answered. A metaphysician is dangerous as long as he or she adopts an attitude unfavorable for others and uses his or her beliefs in order to deprive them of "freedom" (in this unusual sense), to impose his or her point of view on them by means of violence. But a constructivist or Rorty's ironist may be just as dangerous.

As we know, Rorty's ironist appears in his texts as in opposition to the metaphysician, seeking a single, unchanging universal truth. The ironist is aware of the accidental character of his/her beliefs, as well as their historical and cultural roots. When describing such a person, Rorty claims that it is necessary to be aware of the "accidentality" of our opinions and he claims to be doubtful about the beliefs and judgments held (adopting the attitude of the ironist). ${ }^{37} \mathrm{He}$ also claims that it is only when we are uncertain about these beliefs and judgments, when we think that it may be our opponent who is right (and the opponent thinks that we may be right), that none of the parties will resort to violence in order to impose a position on the other. However, Rorty is incorrect since, as I explained above, it is not our beliefs, our opinions, or our certainty or uncertainty that determine whether we use violence. Violence may be inflicted even when we are uncertain, and regardless of whether the aim it supposedly serves is worthy of our engagement. Violence may also be inflicted when one is certain of one's attitude, position, view of reality, treating it as an exemplification or embodiment of this certainty.

In short, it is not necessary to live in uncertainty or to accept it in order to refrain from violence, or to use it. We can also be certain of our position while either using violence or refraining from it. For there is nothing wrong in being certain, as long as our certainty or uncertainty is accompanied by a readiness to meet the other, learn about and verify other opinions and their use, as this is what our attitude should be. At the same time, we should always be ready to extend our knowledge, to wish to learn, never abandoning this endeavor.

In terms of changing Rorty's perspective, and going beyond it, we can say that our actions do not depend on our beliefs about objective and universal reality, and they do not depend on our beliefs about its culturally constituted character, but on the way these beliefs are used. For no belief obliges us to act in a given way. It is therefore not beliefs that are wrong, but the way they are used. Accordingly, we should not fight a belief, but certain attitudes that are aimed at the appropriation of the private sphere of others or at disrupting the common communication space created between us within the public sphere. We should act to change those uses of shared (and unshared) beliefs that lead to violence and, regardless of the vision of the world we have, aim to make both the creation of space for freedom and the equal treatment of other people an important aspect of our actions.

In short, there is no direct transition from beliefs to actions. The former do not determine the latter. There is no justification for Rorty's worries that truth or universal values lead to fundamentalist attitudes and, consequently, to wars. We can promote the rejection of the notion of truth (as disgraced for some) in the field of socio-political action, as Rorty does, but such a rejection gives us nothing valuable, since the beliefs

${ }^{37}$ See, for instance Rorty (1989): 80. 
that we share are not of much political importance. We should realize that what is important are our attitudes, that they are the result of our treatment of the beliefs we hold, the way in which we use them, as well as the interests that we are guided by. We should pay attention to the fact that it is not the categories or beliefs that are responsible for the course of events, but our lack of awareness as to the process of choosing attitudes and actions, over which we have an influence. What counts is how we use our beliefs. There is no reason to fear references to truth. Ultimately, what counts is the interest in whose name it will be used.

Let us return to the supposed success that the ideologies of the $20^{\text {th }}$ century enjoyed for some time. It has been said that this success was achieved due to "promoting" (imposing!) content disseminated in the course of this operation. The success was based on making individuals realize that the battle is fought for them, that they are of the highest value, for the sake of which favorable circumstances for their development should be created. Undoubtedly, it must have been difficult at that time to judge whether the methods applied in order to achieve that goal were right, or whether the goal itself is right. It was believed to be so, although some doubts did arise as well. We share the same doubts today. It is difficult to state what goals and what means used in order to achieve those goals are right. Everywhere someone is trying to present goals and to offer particular methods of action. Accordingly, we ask ourselves the same question again: what does it mean today to act in accordance with a maxim that would become a "universal law"? How can we determine which of the rules and methods of action on offer are worth our attention, and which are not? History teaches us that they are often presented with the conviction that the motivation for implementing them is for the sake of the individual. But are they actually for anyone's sake?

When trying to answer such questions, we can agree with Rorty that what we may rely on is dialog. It is dialog, despite all the problems it involves, that allowes us, to some extent, to get to know each other and to aim to create a situation in which the ubiquitous violence and suffering from coercion can be reduced. It is dialog that can provide us with the opportunities for extending the community, where we refer to a "we" via including in it all those "others" that used to be excluded from it. It is a genuine challenge to form such communities, societies that will deem this dialog to be a necessary element in resolving conflicts under the conditions mentioned above.

\section{References}

Auxier R., Hahn L. (eds) (2010), Philosophy of Richard Rorty. Library of living philosophers, Open Court Publishing Company, Chicago.

Berlin I. (1991), "Two Concepts of Liberty," [in:] Liberty, D. Miller (ed), Oxford University Press, Oxford: 33-57.

Berlin I. (1998), The Sense of Reality, Studies in Ideas and Their History, Farrar, Straus and Giroux, New York.

Brandom R. (2000), Rorty and His Critics, Blackwell Publishing, Oxford.

Curtis W. (2015), Defending Rorty: Pragmatism and Liberal Virtue, Cambridge University Press, Cambridge.

Deliege R. (2001), The Untouchables of India, Berg 3PL, Oxford. 
Deva S. (2012), Regulating Corporate Human Rights Violations: Humanizing Business, Routledge, New York.

Engel P. (2007), What's the Use of Truth?, Columbia University Press, New York.

Fromm E. (1994), Escape from Freedom, Henry Holt Company Inc, New York.

Gebel E. (1946/1983), "Letter to Robert Scholl," trans. A.R. Schultz, [in:] I. Scholl, The White Rose. Munich, 1942-1943, University Press of New England, Lebanon, New Hempshire: $138-147$.

Guignon Ch., Hiley D. (2003), Richard Rorty (Contemporary Philosophy in Focus), Cambridge University Press, Cambridge.

Gross N. (2008), Richard Rorty: The Making of an American Philosopher, University of Chicago Press, Chicago.

Habermas J. (1981), Theory of Communicative Action, trans. T. McCarthy, Beacon Press, Boston. Hanser R. (2012), A Noble Treason: The Story of Sophie Scholl and the White Rose Revolt Against Hitler, Ignatius Press, San Francisco.

Kaiser R. (1987), “A Fifth Gospel, Almost Chief Seattle's Speech(es): American Origin and European Reception," [in:] Indians and Europe: An Interdisciplinary Collection of Essays, Ch. Feest (ed), Heredot im Rader Verlag, Aachen: 505-526.

Kennedy D. (2004), "Human Rights, Part of the Problem?” [in:] D. Kennedy, The Dark Sides of Virtue, Reassessing International Humanitarianism, Princeton University Press, Princeton \& Oxford.

Kilanowski M. (2013), Ku wolności jako odpowiedzialności. Dewey, Rorty, Habermas o nowej jakości w demokracji, Wydawnictwo UMK, Torun.

Kilanowski M. (2015), “Towards a Responsible and Rational Ethical Discussion - A Critique of Putnam's Pragmatic Approach," [in:] Philosophy of Hilary Putnam, Library ofliving philosophers, R.E. Auxier, D.R. Anderson, L.E. Hahn (eds), Open Court Publishing Company, Chicago: 827-862.

Kilanowski M. (2017), “What Kind of Politics Do We Need? Toward Freedom as Responsibility in Habermas's and Rorty's Visions of Democracy," Kultura i Edukacja - Culture and Education 116 (2): 50-68.

Kiobel v. Royal Dutch Petroleum Co., 133 S.Ct. 1659 (2013).

Lamb R. (2009), “For and Against Ownership: William Godwin's Theory of Property,” The Review of Politics 71 (2): 275-302.

Nałkowska Z. (2000), Medallions, trans. D. Kuprel, Northwestern University Press, Evanston IL. Ortega y Gasset J. (1994), The Revolt of the Masses, W. W. Norton \& Company, New York.

Osiatyński W. (2009), Human Rights and Their Limits, Cambridge University Press, New York.

Pable A. (2015), "Integrating Rorty and (Social) Constructivism: A View from Harrisian Semiology," Social Epistemology 29 (1): 95-117.

Proudhon P.-J. (2008), What Is Property?: An Inquiry Into the Principle of Right and of Government, Forgotten Books, London.

United States, Congress, House, Committee on Un-American Activities (1946), Publications Relating to Various Aspects of Communism 15 (1), Washington.

Rorty R. (2008), An Ethics for Today, Columbia University Press, New York.

Rorty R. (1992), "A Pragmatist View of Rationality and Cultural Difference," Philosophy East and West 42 (4): 581-596.

Rorty R. (1989), Contingency, Irony and Solidarity, Cambridge University Press, Cambridge.

Rorty R. (1996), Debating the State of Philosophy: Habermas, Rorty and Kolakowski, J. Niźnik, T. Sanders (eds), Praeger Publishers, Westport. 
Rorty R. (1991), Essays on Heidegger and Others, Cambridge University Press, Cambridge.

Rorty R. (1993), "Human Rights, Rationality, and Sentimentality," [in:] R. Rorty, On Human Rights: The Oxford Amnesty Lectures, S. Shute, S. Hurley (eds), Basic Books, New York: 111-134.

Rorty R. (1997), “Is it Desirable to Love Truth?” [in:] R. Rorty, Truth, Politics and 'Post-Modernism', Van Gorcum, Assen: 11-33.

Rorty R. (1991), Objectivity, Relativism, and Truth, Cambridge University Press, Cambridge.

Rorty R. (2015), “Putnam, Pragmatism and Parmenides," [in:] Philosophy of Hilary Putnam, R.E. Auxier, D.R. Anderson, L.E. Hahn (eds), Open Court Publishing Company, Chicago: 863-881.

Shklar J. (1976), Legalism, Harvard University Press, Cambridge MA.

Srivastava B.N. (1997), Manual Scavenging in India: A Disgrace to the Country, Concept Publishing Company, New Delhi. 